\title{
The Psycheyana: Historical Roots of Contemporary Mindfulness Practices and Future Implications for Social Work Education
}

\author{
John Paulson ${ }^{1}$ \\ ${ }^{1}$ Social Work Department, University of Southern Indiana, Evansville, Indiana, USA \\ Correspondence: John Paulson, Social Work Department, University of Southern Indiana, Evansville, IN 47712 , USA. \\ Tel: 1-812-465-7103.
}

Received: June 23, 2016

Accepted: July 6, 2016

Online Published: July 20, 2016

doi:10.5430/irhe.v1n2p149

URL: http://dx.doi.org/10.5430/irhe.v1n2p149

\begin{abstract}
Mindfulness-based interventions are now an established component of several current psychotherapies. While these technologies come from numerous wisdom, spiritual and contemplative traditions, the developers of mindfulness programs have consistently acknowledged the predominantly Buddhist origins of these approaches. Recent authors have focused more specifically and intentionally on Buddhist principles and their utility in psychological science. This article briefly reviews some historical roots of contemporary mindfulness principles and practices from the Buddhist tradition, explores implications for social work and counselor education, and considers the possibility for psychology and psychotherapy becoming a modern vehicle for the expression of Buddhism.
\end{abstract}

Keywords: mindfulness, Buddhism, social work education

\section{Mindfulness-Based Interventions}

Mindfulness-based interventions (MBI's) are now a well-established component of several contemporary approaches to counseling and psychotherapy, including Mindfulness-Based Stress Reduction (MBSR), Mindfulness-Based Cognitive Therapy (MBCT) and its derivatives, Dialectical Behavior Therapy (DBT), Acceptance and Commitment Therapy (ACT) and Compassion-Focused Therapy (CFT). While the developers of each of these approaches have acknowledged the historical roots of MBI's in contemplative practices from a variety of faith and wisdom traditions, the majority of these practices and techniques are derived from the teachings and practices associated with the Buddhist tradition (Holt \& Cottone; 2014; Sears, Tirch \& Denton, 2011). A multitude of outcome studies have demonstrated the efficacy of these approaches for benefiting numerous behavioral and physical health conditions across a wide variety of client populations (Gotink et al., 2015; Keng, Smoski, \& Robins, 2011).

The dialogue between Buddhism and Western psychology has evolved over a number of decades, but it has escalated in pace over the past several years due to the increased inclusion of MBI's in psychotherapy. Several efforts have sought to comprehensively bridge the gap between these two disciplines, including ones originating from the psychoanalytic tradition (Rubin, 1996; Safran, 2003) and most recently the seminal text from Tirch, Silberstein, and Kolts (2015) on integrating Buddhist psychology and the Cognitive-Behavioral traditions. In addition to addressing mindfulness and compassion practices that are now well recognized in psychology, those authors also incorporate several other aspects of Buddhist teachings into the CBT paradigm, including the Four Noble Truths, the Noble Eightfold Path, and principles from Buddhist psychology related to understanding and applying the principles of karma, dharma and observations about defining qualities of the mind. While the text from Tirch, Silberstein and Kolts provides a comprehensive, accessible and applicable overview of these issues, this article seeks to further highlight the historical roots of some of these contemporary practices within the Buddhist tradition.

\section{Remembering to Be Present}

Several contemporary definitions for mindfulness have been offered. Tirch, Silberstein, and Kolts (2015) reference some of these various descriptions from different practitioners, including characterizing mindfulness as "a state of flexible and focused attention" (p. 73) and "an awareness of present experience with acceptance" (p. 12). While these definitions do accurately capture the attributes of mindful awareness, the most recognized definition of mindfulness continues to be the one put forward by Jon Kabat-Zinn, describing mindfulness as a process of paying attention, in a particular way, to the present moment, on purpose, non-judgmentally (Sears, Tirch \& Denton, 2011). 
This definition captures important processes necessary for cultivating and experiencing mindfulness that are very consistent with the historical description offered by the Buddha in his discourse on The Four Establishments of Mindfulness (Satipatthana Sutta). In this discourse the Buddha offers the follow directions:

... He dwells contemplating (the body, breath, feelings, etc.), ardent, clearly comprehending and mindful, having subdued longing and dejection...just mindful he breathes in, mindful he breathes out. Breathing in long, he understands 'I breathe in long'; or breathing out long, he understands: 'I breathe out long.' Breathing in short, he understands: 'I breathe in short'; or breathing out short, he understands: 'I breathe out short.' He trains thus... (Bodhi, 2005, p. 281-282)

Each of these descriptions emphasizes three main components to mindfulness, namely intent, effort and a non-evaluative, non-attached awareness (see Table 1).

Table 1. Comparing contemporary and historical descriptions of mindfulness

\begin{tabular}{|c|c|}
\hline Jon Kabat-Zinn description & Satipatthana Sutta description (Bodhi, 2005) \\
\hline $\begin{array}{l}\text { Process of paying attention, in a particular way, } \\
\text { to the present moment }\end{array}$ & "...contemplating...clearly comprehending and mindful..." \\
\hline On purpose & "...ardent...thus (the practitioner) trains..." \\
\hline Non-judgmentally & $\begin{array}{l}\text { "...having subdued longing and dejection...just mindful (the } \\
\text { practitioner) breathes in, mindful (the practitioner) breathes } \\
\text { out. Breathing in long, (the practitioner) understands: 'I } \\
\text { breathe in long'; or breathing out long, (the practitioner } \\
\text { understands: 'I breathe out long.' Breathing in short, (the } \\
\text { practitioner understands) 'I breathe in short'; or breathing out } \\
\text { short, (the practitioner) understands: 'I breathe out short'..." }\end{array}$ \\
\hline
\end{tabular}

The historical term translated as mindfulness, sati, conveys a sense of remembering to be present to the moment as it is. Emphasizing that mindfulness, to a degree, requires effort seems important because while mindfulness is ultimately a natural, effortless, ever-present and ever-available state of awareness, it often needs to be cultivated and strengthened in order to counteract conditioned patterns and habits of mind that support not being present to the moment and being overly identified with evaluative thinking. Through intentional development this spontaneous state of awareness becomes more prevalent and more profound (Sears, 2014).

\section{Mindful Coping Skills}

In addition to general mindfulness strategies the application of MBI's has now also expanded to include a focus on the cultivation of compassion and loving-kindness practices. In Buddhist teachings, texts and training compassion (referred to as karuna in Sanskrit and Pali) and loving-kindness (referred to as maitri in Sanskrit and metta in Pali) are both qualities of mind that are promoted because they are seen as antidotes which help to both counter condition and extinguish habitual mental tendencies that create and sustain emotional suffering, thereby support an awakened worldview that promotes liberation from psychological distress. Compassion and loving-kindness are often categorized within the Buddhist tradition in a list of four attributes known as the Brahmaviharas, or "heavenly abodes," along with the additional qualities of sympathetic joy and equanimity. The Brahmaviharas are also commonly referred to as The Four Immeasurables or The Four Limitless Ones because the capacity for experiencing, developing and expressing these qualities is seen as being limitless and immeasurable (Hanh, 1998; Rahula, 1974).

Similar to MBSR and MBCT curricula, structured programs focused on the application of compassion and loving-kindness practices have now been developed and systematically investigated, most notably Neff and Germer's (2013) eight-week Mindful Self-Compassion (MSC) program and Jazaieri and colleague's Compassion Cultivation Training (CCT) program (Jazaieri et al.,2013). Outcome studies for MSC (Neff \& Germer, 2013) and CCT (Jazaieri et al., 2013; Jazaieri et al., 2014) have consistently demonstrated the ability of these programs and practices to increase ratings of mindfulness, compassion, self-compassion, happiness and life satisfaction while decreasing reports of depression, anxiety, stress and emotional avoidance.

Interventions focused more specifically on a related compassion practice called loving-kindness mediation (LKM) have also demonstrated reductions in depression and PTSD symptoms among veterans (Kearney et al., 2013), as well 
as general overall reductions in reports of self-criticism and improvements in ratings of mindfulness and self-compassion (Kearney et al., 2013; Shahar et al., 2015). A recent meta-analysis of randomized controlled trials involving LKM also established the general efficacy of such programs and practices (Galante, Galante, Bekkers \& Gallacher, 2014). An additional review of studies focusing on the application of techniques derived from practices associated with the Four Immeasurables also supports their positive benefits, while also noting limits in existing studies with regards to sample size and research design (Cheng \& Tse, 2015).

\section{Social Work and Counselor Education}

Information and training on mindfulness and compassion practices is increasingly being integrated into social work (Dylan \& Coates, 2016; Lynn, 2010) and counseling (Lahikainen \& Soysa, 2014; Reilly, 2016) curricula. These practices are being utilized to both strengthen direct practice clinical skills (Gockel, 2015) and to reduce burnout among social work and counseling students and interns (Gockel, Burton, James \& Bryer, 2013; Testa \& Sangganjanavanich, 2016). Fulton and Cashwell (2015) observed a positive relationship between mindfulness, compassion and counselor empathy for master's level counselor interns. With regards to burnout Decker and colleagues found that mindfulness reduced compassion fatigue and increased compassion satisfaction among MSW students (Decker, Brown, Ong, \& Stiney-Ziskind, 2015), and Bonifas and Napoli (2014) found that mindfulness improved quality of life ratings for MSW students despite levels of stress persisting.

Two important areas of emphasis for social work and counseling students with regards to utilizing MBI's in their work with clients are ethical issues related to not imposing practices on clients that might be counter to their beliefs or preferences and ensuring competent use of these practices. Social workers are directed to respect the autonomy of clients and aspire not to impose their opinions, beliefs or worldviews on clients (National Association of Social Workers, 2014). Some clients might resist MBI's due to their meditation-like quality and Buddhist origins and see them as conflicting with their own faith heritage. In such cases it is best for the clinician to respect the client's wishes and choose an alternative modality or intervention (Paulson, 2015; Sears, 2015).

Social workers are expected to practice within the scope of their training and competency (National Association of Social Workers, 2014). With the recent proliferation of MBI's there has been concern over clinicians' competency in appropriately utilizing these modalities. In addition to training and self-study recent competency standards suggested for MBI's include securing adequate supervision and being a participant in a structured MBI curriculum before implementing such services. This point underscores the primary competency recommendation that clinicians utilizing MBI's need to have their own established, consistent mindfulness practice. This not only allows the clinician to relate to challenges that clients will face, but also allows the clinician to speak from personal experience and to model these approaches and their utility (Evans et al., 2015; Sears, 2015).

\section{The Psycheyana}

Over the millennia, since the historical Buddha first shared his realizations on the nature of psychological suffering, there have been several different schools of thought on how best to present and practice his teachings. Historically these have come to be known generally as the three vehicles (yanas): the Theravada (Way of the Elders), the Mahayana (Great Vehicle) and the Vajrayana (Diamond Thunderbolt Vehicle). While each of these approaches share the same core teachings, they differ in the various methods they have developed for organizing, interpreting, and expressing the teachings and practices associated with the Buddha (Hahn, 1998; Tirch, Silberstein, \& Kolts, 2015). Over time the Buddha's teachings have survived and flourished due to their ability to evolve. As the teachings spread outside of India into new countries they adapted and evolved to best address and meet the needs and circumstances of the various peoples and cultures they encountered (Armstrong, 2001; Tirch, Silberstein, \& Kolts, 2015).

Given this evolutionary capacity of Buddhism it is possible that modern Western neuroscience, psychotherapy, psychology, social work, counseling, and the other allied helping professions could become the next major vehicle for expressing and offering the teachings of the Buddha, a Psycheyana perhaps. The utilization of Buddhist technologies in psychological science and counseling and therapy interventions could be yet another great example of the adaptability of these teachings to the cultural and historical understandings of the time. This synthesis may be well on its way as the insights and practice technologies of Buddhism have now been systematically researched and applied in behavioral health for over three decades. This has offered a contemporary, secular, scientific context for understanding their utility (Sears, 2014). Tirch, Silberstein, and Kolts (2015) entertain the possibility of this union when they suggest:

Both Buddhist psychology and CBT aim to observe, question and alleviate the experience of suffering by providing a clearer understanding of reality and creating an effective context to cultivate new approaches to 
one's struggles and personal development...from this point forward, at least in the Western world, it may be that CBT and Buddhism are evolving into one another (p. 8).

\section{Cautions}

This synthesis does, however, invite pause to ensure that both traditions are being effectively utilized and that the strengths and attributes of each are being maximized while also avoiding or minimizing the limits and shortcomings inherent in each. Although psychology and Buddhism have much in common, there are also many differences and points of divergence between the two heritages, as each developed in its own unique contexts while serving similar yet separate functions and roles. Steven C. Hayes affirms the skillfulness of such a deliberate and intentional pause, stating:

No one invited therapists to become spiritual leaders, so we cannot enter this territory in exactly the same way as do teachers in the mindfulness tradition. And it would not make sense to import methods that are thousands of years old into a scientific and professional discipline without taking the time to integrate the two" (Sears, Tirch \& Denton, 2011, p. xiii).

Evans et al (2015) also draw attention to the developmental challenge in this transition of roles with their observation that "mindfulness within a secular setting, such as healthcare, is still a new field. As it grows, some interesting challenges arise around holding the essential essence of these programs whilst also adapting to new populations and contexts" (p. 576).

Some suggest caution here due to the before mentioned ethical guidelines shared by social work, counseling and all the allied helping professions to avoid making sure not to impose theology or faith on clients or practitioners. This concern comes primarily out of seeing Buddhism as solely a religious tradition, and conceptualizing it this way places it in direct conflict with other such traditions. While Buddhism has always been classified as one of the world's major religions, and while many of its adherents throughout Asia and the rest of the world practice it as such, the establishment of a new religion was not the historical Buddha's aspiration. In fact his teachings were intended as a reform of and a departure from the multitude of faith traditions that existed at the time. The Buddha never claimed to be a God, a savior, or any type of supernatural being. When others would ask him whether he was a divine being or not, he would simply say that he was awake. He insisted that the capacity to awaken was a human potential that could be achieved by anyone without the existence or intervention of any God (Armstrong, 2001).

\section{Experiential Empiricism}

The Buddha did not aspire to preach theology, insisting instead that he taught only suffering and the cessation of suffering. When the Buddha was asked about theological concepts, such as the existence of God, heaven the soul and afterlife it is said that he kept a noble silence, refusing to answer these questions. In a classic story one of the Buddha's students insisted that he would no longer study with the Buddha until he answered a number of such theologically-oriented questions. In this exchange the Buddha reminded this student that he never promised to provide such answers, and he compared the student's refusal to study with him until such questions were answered to a soldier wounded by an arrow in battle who will not let the physician tend to his wound and remove the arrow until he knew the exact characteristics of the arrow, bow and soldier who shot him (Rahula, 1974).

In another classic account the Buddha came to a village where the residents asked for his guidance on philosophical and spiritual issues. They described their frustration and confusion over the conflicting nature of teachings that various traveling spiritual leaders had offered. They asked the Buddha what they should believe, and he instructed them to not take any teachings on faith or authority, not even his. He emphasized that they would come to realize the efficacy and utility of any teachings through systematically applying those principles to their own lives and experiencing the results directly for themselves (Rahula, 1974).

This directive to gather one's own data on the efficacy of practices and principles based on direct experience is also echoed in the Tibetan Lojong slogan that suggests "of the two witnesses, hold the principal one," meaning that the individual should give priority to their own experiences with the teachings and practices over the beliefs and conjectures of others (Chodron, 2003). This illustrates that the Buddha was not looking to establish dogmas or articles of faith, but that he was encouraging an experiential empiricism, one very consistent with psychotherapy generally and the cognitive-behavioral tradition especially (Tirch, Silberstein, \& Kolts, 2015).

\section{Conclusion}

Social workers and counselors in training now have a wide variety of mindfulness and compassion practices at their disposal. They can be assured that these approaches are based on extensive research and have been empirically supported to help improve a multitude of psychological and physical health issues. In addition to alleviating distress MBI's have also been shown to promote psychological well-being and improve quality of life for not only clients, 
but also for clinicians. While these approaches can be very useful and effective, the practitioner is cautioned to utilize them in a competent manner sensitive to client wishes and preferences. For these reasons education and training on MBI's are now being more widely included in social work and counseling curricula.

The prolific research on mindfulness and compassion and the adoption of these practices in a multitude of intervention approaches suggests that the tenets of Buddhism may have wide applicability to the science of psychology, even in a contemporary environment where its religious underpinnings are abandoned. Some have suggested that the robust findings on mindfulness warrant the development of a science of mindfulness-based interventions, and that such an effort would allow for more coordination between researchers on identifying continued areas for exploration (Dimidjian \& Segal, 2015). Through the vehicle of science a contemporary, Western expression of the teachings of the Buddha makes it possible to interpret the term "Buddhist" as more a statement about a systematic approach to understanding human consciousness, behavior, and psychological well-being rather than a statement of theology or identification with a faith tradition. In a contemporary Western context to say that one is a Buddhist is becoming more akin to saying that one is a psychoanalyst than to saying one is a Christian or Muslim.

The compassionate efforts of a multitude of authors and researchers have now made it clear that principles and practices derived from the Buddhist tradition can be seen to represent qualities of awareness and patterns of overt and covert behavior that can not only be systematically observed and studied, but can also be intentionally cultivated and utilized to decrease psychological distress and improve psychological functioning and well-being. Buddhism may come to be best understood as a type of psychology and its practices as a form of psychotherapy. Regardless of whether or not contemporary psychological science and therapeutic practice become the next great vehicle of transmission for Buddhism, it is clear that the teachings of the Buddha will continue to inform and enrich the western scientific and therapeutic traditions.

\section{References}

Armstrong, K. (2001). Buddha. New York, NY: Penguin.

Bodhi, B. (2005). In the Buddha's words: An anthology of discourses from the Pali canon. Boston, MA: Wisdom Publications.

Bonifas, R. P., \& Napoli, M. (2014). Mindfully increasing quality of life: A promising curriculum for MSW students. Social Work Education, 33(4). 469-484. http://dx.doi.org/10.1080/02615479.2013.838215

Cheng, F. K., \& Tse, S. (2015). Applying the Buddhist four immeasurables to mental health care: A critical review. Journal of Religion and Spirituality in Social Work: Social Thouht, 34(1), 24-50. http://dx.doi.org/10.1080/15426432.2014.921128

Chodron, P. (2003). Comfortable with uncertainty: 108 teachings on cultivating fearlessness and compassion. Boston, MA: Shambhala.

Decker, J. T., Brown, J. C., Ong, J., \& Stiney-Ziskind, C. A. (2015). Mindfulness, compassion fatigue, and compassion satisfaction among social work interns. Social Work \& Christianity, 42(1). 28-42.

Dimidijian, S., \& Segal, Z.V. (2015). Prospects for a clinical science of mindfulness-based intervention. American Psychologist, 70(7), 593-620. http://dx.doi.org/10.1037/a0039589

Dylan, A., \& Coates, J. (2016). Conclusion to special issue: Mindfulness and social work. Journal of Religion \& Spirituality in Social Work: Social Thought, 35(1-2), 132-133. d http://dx.doi.org/10.1080/15426432.2016.1127093

Evans, A., Crane, R., Cooper, L., Mardula, J., Wilks, J. Surawy, C., Kenny, M., \& Kuyken, W. (2015). A framework for supervision for mindfulness-based teachers: A space for embodied mutual inquiry. Mindfulness, 6, 572-581. http://dx.doi.org/10.1007/s12671-014-0292-4

Fulton, C. L., \& Cashwell, C.S. (2015). Mindfulness-based awareness and compassion: Predictors of counselor empathy and anxiety. Counselor Education and Supervision, 54(2), 122-133. http://dx.doi.org/10.1002/ceas.12009

Galante, J., Galante, I., Bekkers, M., \& Gallacher, J. (2014). Effects of kindness-based meditation on health and well-being: A systematic review and meta-analysis. Journal of Consulting and Clinical Psychology, 82(6), 1101-1114. http://dx.doi.org/10.1037/a0037249

Gockel, A. (2015). Teaching note-practicing presence: A curriculum for integrating mindfulness training into direct practice instruction. Journal of Social Work Education, 51(4), 682-690. 
Gockel, A., Burton, D., James, S., \& Bryer, E. (2013). Introducing mindfulness as a self-care and clinical training strategy for beginning social work students. Mindfulness, 4(4), 343-353. http://dx.doi.org/10.1007/s12671-012-0134-1

Gotink, R.A., Chu, P., Busschbach, J.V., Benson, H., Fricchione, G.L., \& Hunick, M.M. (2015). Standardised mindfulness-based interventions in healthcare: An overview of systematic reviews and meta-analyses of RCT's. Plos ONE, 10(4), 1-17. http://dx.doi.org/10.1371/journal.pone.0124344

Hanh, T. N. (1998). The heart of the Buddha's teachings: Transforming suffering into peace, joy, and liberation. New York, NY: Broadway Books.

Holt, R.W., \& Cottone, R.R. (2014). Mindfulness: An overview for human services professionals. Journal of Human Services, 34(1), 52-69.

Jazaieri, H., Jinpa, G.T., McGonigal, K., Rosenberg, E.L., Finkelstein, J., Simon-Thomas, E., \& Goldin, P.R. (2013). Enhancing Compassion: A randomized controlled trial of a compassion cultivation training program. Journal of Happiness Studies, 14(4), 1113-1126. http://dx.doi.org/10.1007/s10902-012-9373-z

Jazaieri, H., McGonigal, K., Jinpa, T., Doty, J., Gross, J., \& Goldin, P. (2014). A randomized controlled trial of compassion cultivating training: Effects on mindfulness, affect, and emotion regulation. Motivation \& Emotion, 38(1), 23-35. http://dx.doi.org/1007/s11031-013-9368-z

Kearney, D.J., Malte, C.A., McManus, C., Martinez, M.E., Felleman, B., \& Simpson, T.L. (2013). Loving-kindness meditation for post-traumatic stress disorder: A pilot study. Journal of Traumatic Stress, $26(4), 426-434$. http://dx.doi.org/10.1002/jts.21832

Keng, S., Smoski, M.J., \& Robins, C.J. (2011). Effects of mindfulness on psychological health: A review of empirical studies. Clinical Psychology Review, 31, 1041-1056.

Lahikainen, K., \& Soysa, C.K. (2014) Teachings undergraduates about mindfulness. Journal of Human Services, $34(1), 5-23$.

Lynn, R. (2010). Mindfulness in social work education. Social Work Education, 29(3), 289-304.

National Association of Social Workers. (2014). Code of Ethics of the National Association of Social Workers. Washington D.C. NASW Press.

Neff, K.D., \& Germer, C.K. (2013). A pilot study and randomized controlled trial of the Mindful Self-Compassion Program. Journal of Clinical Psychology, 69(1), 28-44.

Paulson, J. (2015). Skillful means: Expanding the application of mindfulness practices in Human Services. Journal of Human Services, 35(1), 107-111.

Rahula, W. (1974). What the Buddha Taught. New York, NY: Grove Press.

Reilly, B. (2016). Mindfulness infusion through CACREP standards. Journal of Creativity in Mental Health, 11(2), 213. http://dx.doi.org/10.1080/15401383.2016.1139482

Rubin, J.B. (1996). Psychotherapy and Buddhism: Toward and integration. New York, NY: Plenum Press.

Safran, J. D. (2003). Psychoanalysis and Buddhism: An unfolding dialogue. Boston, MA: Wisdom Publications.

Sears, R. (2014). Mindfulness: Living through challenges and enriching your life in this moment. London, UK: Wiley-Blackwell.

Sears, R. (2015). Building competence in mindfulness-based cognitive therapy: Transcripts and Insights for working with stress, anxiety, depression and other problems. New York, NY: Routledge.

Sears, R.W., Tirch, D.D., \& Denton, R.B. (2011). Mindfulness in clinical practice. Sarasota, FL: Professional Resource Press.

Shahar, B., Szepsenwol, O., Zilcha-Mano, S., Haim, N., Zamir, O., Levi-Yeshuvi, S., \& Levit-Binnun, N. (2015). A wait-list randomized controlled trial of loving-kindness meditation programme for self-criticism. Clinical Psychology \& Psychotherapy, 22(4), 346-356. http://dx.doi.org/10.1002/cpp.1893

Testa, D., \& Sangganjanavanich, V. F. (2016). Contributions of mindfulness and emotional intelligence to burnout among counseling interns. Counselor Education and Supervision, 55(2), 95-108. http://dx.doi.org/10.1002/ceas.12035

Tirch, D., Silberstein, L.R., \& Kolts, R.L. (2015). Buddhist psychology and cognitive-behavioral therapy: A clinician's guide. New York, NY: Guilford Press. 